\title{
Fight or flight? Market positions, submarket interdependencies, and strategic responses to entry threats
}

\section{Sendil Ethiraj $^{1}$ | Yue Maggie Zhou ${ }^{2}$}

\footnotetext{
${ }^{1}$ Strategy and Entrepreneurship Department, London Business School, London, UK

${ }^{2}$ Strategy Department, Stephen M. Ross

School of Business, University of

Michigan, Ann Arbor, Michigan

Correspondence

Yue Maggie Zhou, Stephen M. Ross School of Business, University of Michigan,

701 Tappan St., Ann Arbor, MI 48109.

Email: ymz@umich.edu
}

\begin{abstract}
Research Summary: This paper examines how incumbent firms' market positions and interdependencies across their submarkets influence their responses to entry threats. We adapt a model of capacity deterrence to show that because premium and low-cost incumbents face different demand functions and operating costs, they experience different tradeoffs between ignoring, deterring, and accommodating threatened entry. In addition, the interdependencies within and between a premium incumbent's submarkets influence its responses. Using data on incumbent responses to entry threats from Southwest Airlines between 2003 and 2012, we find that (a) full-service incumbents expanded capacity while low-cost incumbents did not respond significantly, and (b) full-service incumbents expanded capacity less aggressively in submarkets that had less substitutable customer segments and submarkets that were more complementary with their unthreatened submarkets.
\end{abstract}

Managerial Summary: An immutable market position is a core competitive advantage. Using data on incumbent responses to entry threats from Southwest Airlines between 2003 and 2012, we find that (a) full-service (FSC) incumbents expanded capacity while low-cost (LCC) incumbents did not respond significantly, and (b) FSCs expanded capacity less aggressively on routes that were expected to have a large number of business passengers and routes that connected to their international hubs. These results suggest two sources of positional 
immutability: While one set of past choices (e.g., those about submarket substitutability or complementarity) provide a barrier against imitation, another set of past choices (e.g., those about products and costs) generate incentives for a tough defense, both deterring entry by firms from a different position.

\section{K E Y W O R D S}

airlines, competitive interaction, entry deterrence, interdependence, market position

\section{1 | INTRODUCTION}

A classic prescription for attaining competitive advantage is for firms to identify and enter an attractive industry, and to identify and occupy an attractive market position within that industry (Porter, 1980). A market position aggregates a distinct set of interdependent strategic choices including choices about resources, prices, quality, and submarkets ${ }^{1}$ (Porter, 1980). The interdependencies and tradeoffs among these choices are assumed to serve as a barrier to imitation and entry by firms from different positions, thereby sustaining the position's competitive advantage (Porter, 1985, 1991): Firms seeking to migrate across positions will face a "repositioning cost" in changing their historical choices about resources, prices, quality, and submarkets (Menon \& Yao, 2017). Despite the large body of research on market positions, the crucial assumption that market positions are largely insulated from direct competition from other positions and that competitive interaction occurs mostly within rather than across positions has yet to be formally explored and empirically tested. In an effort to improve our understanding of the sources of immutability that protect market positions, this paper examines how the dynamics of competitive interaction vary within and across market positions.

We note that there is a vibrant and growing literature on competitive interactions (see excellent reviews by Chen and Miller (2012, 2015); and more recent work by Makadok and Ross (2018)). While this literature has resulted in a better understanding of competitive dynamics within industries and the articulation of a theoretical framework (the Awareness-Motivation-Capability model), there is limited cross-pollination with the literature on market positions. For example, the multimarketcontact literature is more concerned with competitive interaction between firms across multiple overlapping submarkets than competitive interaction within each submarket arising from positional differences (Gimeno \& Woo, 1999). Similarly, the emerging research about platform competition focuses on firms with different business models such as newspapers and classified advertisement websites rather than firms with different positions (Seamans \& Zhu, 2017). In addition to general positional differences, differences in submarket interdependencies, or interdependences existing either between segments within the same submarket or between different submarkets that a firm operates in, are understudied. To the extent that market positions reflect mutually reinforcing, interdependent choices (Ghemawat \& Levinthal, 2008), a focus on interdependencies among

\footnotetext{
${ }^{1}$ Throughout this paper, the word "market" refers to the entire market in an industry when it appears in the phrase "market position." The word "submarket" refers to individual markets in different locations or product categories operated by a firm.
} 
position-specific choices, including choices of submarkets, will help us understand how competitive interactions vary within and across market positions.

Against this background, the current paper examines the impact of market positions and submarket interdependencies on one specific form of competitive interaction-entry deterrence. We adopt a multi-method approach, first developing the theory through a formal model and then testing the predictions using data from the U.S. airline industry. We adapt a classic model of capacity response to entry threat (Dixit, 1980; Spence, 1977) by introducing two enhancements. First, we allow incumbents to occupy different market positions-premium versus low-cost-with interdependent demand and cost consequences. This affords examination of intra-industry heterogeneity in competitive responses from incumbents with different market positions to entry threats. Second, we allow incumbents to differ in the degree of interdependencies within and between the submarkets they choose to operate in. This results in heterogeneous competitive responses from the same incumbent across different submarkets.

We make two important assumptions about the differences between premium and low-cost firms. First, we assume that premium and low-cost firms face different demand curves: Consumers of premium products are less price sensitive than consumers of low-cost products. Second, we assume that premium firms incur higher operating costs than low-cost firms: Product or service differentiation is costly. Building on these two assumptions, our model predicts that when capacity expansion costs are sufficiently lower than operating costs, a premium incumbent will be more aggressive than a low-cost incumbent in deterring entry. The intuition is that because a premium incumbent has a higher operating cost than a low-cost incumbent, the monopolistic output for the premium incumbent is lower than that of the low-cost incumbent in a similar market, which leaves a bigger residual demand for the entrant and makes the entry more likely. In addition, compared with a low-cost entrant, the premium incumbent's disadvantage in operating cost and advantage in demand (lower price sensitivity) make accommodation less profitable relative to deterrence. As a result, a premium incumbent will be more aggressive than a low-cost incumbent to deter rather than to ignore or accommodate entry.

We then build on this baseline prediction to deepen our understanding of heterogeneity in responses from a premium incumbent across its threatened submarkets. We allow for a premium incumbent to operate in multiple submarkets with different degrees of demand-side interdependencies within and between them. We show that two types of interdependencies moderate a premium incumbent's response. The first type is the substitutability between customer segments within a threatened submarket. If the submarket is largely comprised of customers that strongly prefer the premium product and are unattracted to the product offering of a low-cost entrant, the benefit of an aggressive deterrence response is likely to be outweighed by the forgone profit of an accommodation strategy. However, if a significant share of customers is willing to substitute the premium product with the low-cost product, the benefits of deterrence will outweigh the forgone profit from accommodation. Consistent with these arguments, our model predicts that the degree of substitutability in a premium incumbent's threatened submarket amplifies its incentive to deter entry.

The second type of interdependence is the complementarity between the threatened and unthreatened submarkets that a premium incumbent operates in. If the unthreatened submarkets share a high degree of complementarity with the threatened submarket, the negative effect of entry for the incumbent in the threatened submarket can be counterbalanced by positive effects in complementary submarkets: while losing business volume to an entrant in the threatened submarket hurts local profits for the incumbent, the increase in total demand in this submarket can contribute to the incumbent's business volume in unthreatened submarkets. Consistent with these arguments, our model 
predicts that the degree of complementarity across a premium incumbent's submarkets dampens its incentive to deter entry.

We test these predictions using fine grained data in the airline industry, where there is a clear mapping between market positions and airlines-full-service (premium) carriers (FSCs) and low-cost carriers (LCCs). We examine the capacity responses of FSC and LCC incumbents to submarket(route-) level threat of entry by Southwest Airlines from 2003 to 2012. We find evidence consistent with our predictions. First, FSC incumbents increased seat capacity, while LCC incumbents did not respond significantly to the threat of entry. In addition, there was significant heterogeneity in FSC incumbents' responses across their threatened submarkets. They added less seat capacity on threatened routes that were expected to have a larger proportion of business-class passengers (who are less likely to substitute their demand for premium service with that for low-cost service) and routes that connected to the incumbent' international hubs (where there is high complementarity between the threatened domestic market and the unthreatened international markets).

The paper contributes to several strands of literature. First, it connects the research on entry deterrence in industrial organization with the research on market positions in strategic management. Specifically, we incorporate market positions and submarket interdependencies into a classic model of entry deterrence. We show that incumbent firms' past choices of market positions and submarket interdependencies influence their competitive behavior. These past choices provide two sources of positional immutability: While one set of past choices (e.g., those about submarket interdependencies) generate barriers that prevent firms from a different position to imitate and enter, another set of past choices (e.g., those about products and costs) generate position-specific incentives that encourage a tough defense from the incumbent, thereby deterring entry. We see our effort to both formalize the empirical analyses and operationalize the theoretical model as crucial to understanding the conditions and mechanisms that drive the variation in entry deterrence decisions across different incumbents or across different submarkets for the same incumbent.

In addition, the current paper enriches the competitive dynamics literature in strategy. It implies that by strategically exploiting or avoiding submarket interdependencies, firms can employ a unique set of tools to manage competitive interaction. Furthermore, the paper extends empirical work on entry deterrence through capacity expansion (Kadiyali, 1996; Lieberman, 1987a, 1987b) by studying incumbent response to the threat of entry (rather than actual entry). We also empirically examine a broad range of competitive responses, such as price and quality differentiation, in addition to capacity. This approach offers a comparison with the results in prior studies and a more coherent analysis of competitive responses to entry threat than prior studies.

\section{2 | RELATED LITERATURE}

This paper is mostly related to the research on competitive dynamics in general and entry deterrence in particular. As summarized in Chen and Miller (2012, 2015), much of the existing work on competitive interaction in the strategy literature focuses on three factors: (a) characteristics of the market, (b) characteristics of the attacker, and (c) characteristics of the defender/incumbent. Considerations of market positions and submarket interdependencies are mostly absent.

The literature on response to entry threats is mostly theoretical (e.g., Brander \& Eaton, 1984; Dixit, 1979; Milgrom \& Roberts, 1982; Schmalensee, 1978; Spence, 1977). It explores whether a deterrence or accommodation response is optimal. For instance, an incumbent can deter entry through limit pricing, that is, pricing below the cost of the potential entrant, in order to manipulate the entrant's perception of post-entry profits (Milgrom \& Roberts, 1982). Alternatively, the 
incumbent can accommodate entry by keeping the price at the same level or even raising it, hoping to encourage the entrant to charge a higher price after entry (Pauwels \& Srinivasan, 2004). Incumbents can also invest in excess capacity to signal post-entry output increase and price decrease, thereby deterring entry; such investment is credible when the capacity is irreversible, slowly depreciating, specific to the firm, and in excess of current demand (Dixit, 1979; Mazzeo, 2002).

The empirical evidence on strategic responses to entry threats is sparse and mostly about responses after entry has occurred (e.g., Lieberman, 1987a, 1987b; Lieberman \& Demeester, 1999). Rare exceptions include Seamans (2013), who finds evidence of limit pricing in response to potential entry in the U.S. cable television industry, and Ellison and Ellison (2011), who find that pharmaceutical incumbents increased prices before their branded drug patents expired. Conlin and Kadiyali (2006) use capacity to demand ratio as a proxy for the incumbents' entry-deterrence behavior and find that hotels added more rooms in more-concentrated markets. Few empirical studies have examined heterogeneity among incumbents. Rare exceptions include Simon (2005), who finds that newer magazine publishers cut prices more in response to entry, as they felt more vulnerable than the older incumbents.

There is also a large body of empirical work on the airline industry, with a focus on price or price-cost margin rather than capacity (see Berry \& Jia, 2010 for an important exception). These studies are discussed in detail when we describe the airline context.

\section{I A MODEL OF INCUMBENT RESPONSE TO ENTRY THREAT}

We adapt a formal model of capacity expansion to identify the mechanisms that influence incumbent responses to entry threats. To save space, we provide the details of the model in Appendix S1, Supporting Information. In this section, we explain the key assumptions, results, and intuitions of the model.

We start with the classic single-market model following Dixit (1980) and Spence (1977). In this model, a monopolistic incumbent and a low-cost entrant, both having complete information about each other's costs, ${ }^{2}$ play a two-stage game. Before the game starts, the incumbent operates as a monopoly in the market at capacity $K_{i}^{M}$. In the first stage, facing an entry threat, the incumbent invests in additional capacity $\left(K_{i}-K_{i}^{M}\right)$ at a constant unit cost of $r_{i}$. The entrant observes $K_{i}$ and decides whether to enter with a fixed entry cost of $f$ and a constant average variable cost of $c_{e}$. In the second stage, if entry occurs, the incumbent and the entrant simultaneously choose their output $\left(q_{i}\right.$ and $q_{e}$, respectively) to generate a set of equilibrium outcomes (Stackelberg, 1934). The incumbent's constant average variable cost is $c_{i}$ if $q_{i} \leq K_{i}$ and $c_{i}+r_{i}$ if $q_{i}>K_{i}$. The inverse demand function is given by $P=1-Q$, where $Q=q_{i}+q_{e}$. The incumbent is expected to choose $K_{i}$ using backward induction, as illustrated in Section 1 of Appendix S1.

We plot in Figure 1 a framework to analyze the dynamic process as the entry cost declines from the right of the spectrum to the left. If the entry cost is high enough, entry is not viable for the entrant even with no response from the incumbent, so the incumbent can ignore the threat. When the entry cost drops below $\bar{f}_{D}$ but remains above $\bar{f}_{A}$, the incumbent's monopoly is attainable only via deterrence. When the entry cost drops below $\bar{f}_{A}$, the incumbent will find that accommodation is more profitable. Finally, if entry cost is sufficiently low and the operating cost of the entrant is lower than

${ }^{2}$ This is a reasonable assumption in our context given that the incumbent airlines faced actual competition from Southwest on many routes for at least a decade before our sample period. 


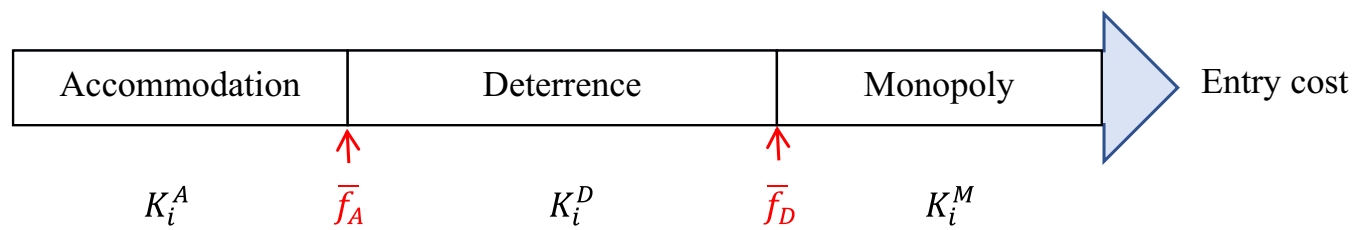

F I G U R E 1 Incumbent's strategic responses as entry cost declines

that of the incumbent, the optimal response of the incumbent may be to exit. We focus on these cutoff points to determine the incumbent's best response. As part of our empirical design, we fix the potential entrant to be one firm, Southwest Airlines, so that the operating cost of the potential entrant, $c_{e}$, is the same for all analyses in the model.

We now extend the basic model and consider the case where the market can support two products, one low cost (Product 1) and one premium (Product 2). A low-cost incumbent and a low-cost entrant will always offer Product 1 and face an inverse demand function of $P_{1}=1-Q_{1}-s Q_{2}$, where $Q_{1}=q_{i}+q_{e}, Q_{2}=0$. A premium incumbent will always offer Product 2 and face an inverse demand function of $P_{2}=1-\theta Q_{2}-s Q_{1}, Q_{1}=q_{e} \cdot \frac{1}{\theta} \in[0,1]$ represents the price sensitivity of consumers for Product 2, relative to Product 1. $\frac{1}{\theta}<1$ means that consumers are less price sensitive for Product 2 than for Product 1. $s \in[0,1]$ represents the degree of substitution between the two products. When $s=0$, the demand functions for the two products are independent: $Q_{1}=1-P_{1}$ and $Q_{2}=\frac{1-P_{2}}{\theta}$, respectively. When $s=1$, the demand functions for Product 1 and Product 2 are: $Q_{1}=1-\frac{\theta P_{1}}{\theta-1}+\frac{P_{2}}{\theta-1}$ and $Q_{2}=\frac{P_{1}-P_{2}}{\theta-1}$, respectively. We compare two scenarios: (a) The monopolist incumbent is a low-cost firm with the same operating cost as the entrant $\left(c_{\mathrm{iL}}=c_{e}\right)$, and (b) the monopolistic incumbent is a premium firm with a higher operating cost than the entrant $\left(c_{\mathrm{iP}}>c_{e}\right)$.

First, as we prove in Section 2 of Appendix S1, the cutoff point between monopoly and deterrence for a low-cost incumbent, $\bar{f}_{D 1}$, is smaller than the cutoff point for a premium incumbent, $\bar{f}_{D 2}$. This means that, as the entry cost declines, the cutoff point for the premium incumbent to deter (rather than ignore) entry, $\bar{f}_{D 2}$, is to the right of the cutoff point for the low-cost incumbent to deter, $\bar{f}_{D 1}$. The intuition is that, because a premium incumbent has a higher operating cost than a low-cost incumbent in a similar market, the monopolistic output of the premium incumbent is lower than that of the low-cost incumbent, which leaves a bigger residual demand for the potential entrant. Therefore, the premium incumbent needs a higher entry cost $\bar{f}_{D}$ to ignore entry. That is, as the entry cost drops, a premium incumbent will start deterring entry earlier than a low-cost incumbent.

Second, we show in Section 2 of Appendix S1 that the cutoff point between deterrence and accommodation for the low-cost incumbent, $\bar{f}_{A 1}$, is larger than the cutoff point for the premium incumbent, $\bar{f}_{A 2}$, when $r_{i}$ is sufficiently small relative to $c_{i}$. Intuitively, when investment costs are sufficiently low (relative to operating costs), the incumbent will find it more profitable to invest in deterrence capacity than to accommodate entry and give up market share. This preference for deterrence over accommodation will be stronger for a premium incumbent, because it will lose a larger market share to the low-cost entrant in a duopolistic market than will a low-cost incumbent. In addition, consumers' lower price sensitivity for a premium product makes accommodation less profitable relative to deterrence for a premium incumbent compared with a low-cost incumbent.

Combining the analysis of $\bar{f}_{D}$ and $\bar{f}_{A}$, we show that $\left(\bar{f}_{D 2}-\bar{f}_{A 2}\right)>\left(\bar{f}_{D 1}-\bar{f}_{A 1}\right)$ when $r_{i}$ is sufficiently small relative to $c_{i}$. That is, the premium incumbent will be more aggressive in deterring (rather than ignoring or accommodating) a low-cost firm's entry than will a low-cost incumbent when capacity 
investment costs are sufficiently small relative to operating costs. It should be noted that this prediction is in contrast with the argument that strategic similarity (i.e., firms occupying the same market position) leads to greater rivalry (Gimeno \& Woo, 1996). The key reason for the difference is that our model explicitly considers the tradeoffs an incumbent faces among ignoring, deterring, and accommodating entry.

Proposition 1. Following the threat of entry from a low-cost entrant, if investment costs are sufficiently low relative to operating costs, a premium incumbent will be more likely to invest in deterrence capacity as compared with a low-cost incumbent.

We now build on the baseline prediction in Proposition 1 to examine the situation where a premium incumbent operates in multiple submarkets, one of which is threatened by a potential low-cost entrant. We examine how two types of demand-side submarket interdependencies amplify or mitigate the incumbent's deterrence incentive. The first type of interdependence is demand substitutability between customer segments within a single threatened submarket, or the degree to which a product targeted for one segment could be substitutable for a product targeted for another segment.

We examine the premium incumbent's aggressiveness in deterrence as the degree of substitution between the product targeted for the premium segment and that for the low-cost segment, $s$, changes. We show in Section 3 of Appendix S1 that $\frac{\partial\left(\bar{f}_{D}-\bar{f}_{A}\right)}{\partial s}>0$ for a majority of feasible cases, implying that the premium incumbent's incentive to deter entry is increasing in the substitutability between the customer segment it chooses to serve and the customer segment that the potential low-cost entrant will serve. The intuition is that, when demand is less substitutable between the two segments, it is more profitable for the premium incumbent to accommodate entry. This is because the cost of deterrence to maintain a monopoly is greater than its expected revenue loss under a duopoly with the low-cost entrant.

Proposition 2. Following the threat of entry from a low-cost entrant, a premium incumbent will be more likely to invest in deterrence capacity when demand substitutability between the premium and low-cost segments in the threatened submarket is high.

A second type of interdependence is the complementarity in demand across the incumbent's submarkets. We operationalize this idea by assuming that the premium incumbent operates and maximizes the joint profits in two submarkets $-j$ and $k$-with complementary demand, and the entrant threatens to operate in submarket $j$. The inverse demand functions in market $j$ are $P_{j 1}=1-Q_{j 1}-s Q_{j 2}$ for the low-cost product and $P_{j 2}=1-\theta Q_{j 2}-s Q_{j 1}$ for the premium product, where $Q_{j 1}=q_{e}$ and $Q_{j 2}=q_{i j 2}$. The inverse demand function in submarket $k$ is $P_{k}=1-\theta Q_{k}+m Q_{j}$, where $Q_{k}=q_{i k}, Q_{j}=Q_{j 1}+Q_{j 2}$, and $m \in[0,1]$ represents the degree of complementarity between the two submarkets. When $m=0$, the demand functions in the two submarkets are independent: $Q_{j 1}=\frac{\theta}{\theta-s^{2}}\left(1-P_{j 1}\right)-\frac{s}{\theta-s^{2}}\left(1-P_{j 2}\right), Q_{j 2}=\frac{1}{\theta-s^{2}}\left(1-P_{j 2}\right)-\frac{s}{\theta-s^{2}}\left(1-P_{j 1}\right), \quad$ and $\quad Q_{k}=\frac{1}{\theta}\left(1-P_{k}\right) . \quad$ When $m=1$, the demand functions in the two submarkets are: $Q_{j 1}=\frac{\theta}{\theta-s^{2}}\left(1-P_{j 1}\right)-\frac{s}{\theta-s^{2}}\left(1-P_{j 2}\right)$, $Q_{j 2}=\frac{1}{\theta-s^{2}}\left(1-P_{j 2}\right)-\frac{s}{\theta-s^{2}}\left(1-P_{j 1}\right), \quad Q_{k}=\frac{1}{\theta}\left(1-P_{k}\right)+\frac{\theta-s}{\theta\left(\theta-s^{2}\right)}\left(1-P_{j 1}\right)+\frac{1-s}{\theta\left(\theta-s^{2}\right)}\left(1-P_{j 2}\right)$, and all consumers in submarket $j$ also demand the product in submarket $k$.

As we prove in Section 4 of Appendix S1, the deterrence interval $\left(\bar{f}_{D}-\bar{f}_{A}\right)$ decreases with $m$ when $r_{i}$ is small enough relative to $c_{i}$ and $m$ is not too small. That is, the premium incumbent will face a narrower range for deterrence if the entrant provides a more complementary product. Put 
differently, the premium incumbent will be better off accommodating than deterring an entrant as the complementarity between the premium incumbent's submarkets increases. To use an example, assume a monopolistic incumbent operates in markets for both coffee and sugar and experiences threat of entry in the market for coffee. The incentive for the incumbent to deter entry in the coffee market is decreasing in the degree of complementarity between the sugar market and the coffee market. This is because the increased demand for sugar would offset the incumbent's lost market share in the coffee market.

Proposition 3. Following the threat of entry from a low-cost entrant, if investment costs are sufficiently low relative to operating costs, a premium incumbent will be less likely to invest in deterrence capacity when there is greater demand complementarity between its threatened and unthreatened submarkets.

In sum, we have proposed a general theory of incumbent responses to entry threats. We show that when capacity investment costs are sufficiently lower than operating costs, an incumbent's response depends on its market position, as well as the interdependencies within and across its submarkets. In the following section, we introduce the empirical setting where these theoretical propositions are translated into empirically testable hypotheses.

\section{4 | THE AIRLINE INDUSTRY}

The airline industry provides an attractive context for our study for several reasons. First, at least during the period of our study, there are two distinct groups of firms, each occupying a market position that has been defined by academic scholars, business practitioners, and policy makers. For example, Federal Aviation Administration statistics are broken down by the categories of FSCs and LCCs. FSCs provide a greater variety of services and network linkages, more legroom, larger planes, a higher percentage of first-class and business-class seats, and frequent flyer programs. FSCs also adopt a multi-hub-and-spoke route structure, whereas LCCs usually offer limited point-to-point services on selected segments.

Second, there is dynamic competition in the airline industry. Air travel is a non-storable product with volatile demand. As a result, price, capacity, and quality of service vary significantly not only across routes, but also across different flights on the same route. There is robust empirical evidence that airlines engage in competition through price-cutting, capacity expansion, and quality differentiation (Ciliberto \& Tamer, 2009; Joskow, Werden, \& Johnson, 1994; Morrison, 2001; Williams, 2013; Windle \& Dresner, 1999). The majority of the empirical studies on airline competition, however, have focused on price or price-cost margin.

Third, since the 1990s, FSCs have been threatened by the growth of LCCs. According to Mueller \& Hüschelrath (2012), from 1997 to 2009, LCCs increased their domestic market share from 13 to 29\%; one of the leading LCCs is Southwest Airlines, which increased its market share from $7 \%$ to $16 \%$. The expansion of Southwest over time provides an opportunity to empirically identify the responses of incumbent carriers to entry threats at the route level.

Finally, the airline industry is heavily regulated, and detailed data on pricing, capacity, and quality are available at the firm-route level. The airline industry has also been the subject of extensive academic research, which provides a benchmark for the current study. 


\section{5 | HYPOTHESES}

Building on the propositions of our model, we derive empirical predictions about incumbents' capacity responses to entry threats from Southwest Airline. We focus on three sources of heterogeneity: variation in the incumbent's market position (premium versus low-cost, as defined by its demand function and operating cost), variation in demand substitutability between customer segments within the threatened submarket of a premium incumbent, and variation in demand complementarity between the premium incumbent's threatened and unthreatened submarkets.

In the airline industry, FSCs provide a premium service and attract consumers who value quality more than price. At the same time, FSCs incur higher operating costs. In contrast, LCCs save operating costs by providing a standardized, low-cost service that is targeted at more price sensitive consumers. According to Proposition 1, when capacity investment costs are sufficiently low relative to operating costs, a premium incumbent (e.g., an FSC incumbent) will be more likely to invest in deterrence capacity as compared with a low-cost incumbent (e.g., an LCC incumbent).

A critical condition of Proposition 1 is that capacity investment costs are sufficiently lower than operating costs. To test the validity of this condition in the airline industry, we investigate actual cost data for Delta, an FSC, and Southwest, an LCC. We find that the average capital costs for both airlines were less than $10 \%$ of their operating costs, satisfying the condition for Proposition $1 .^{3}$

Another critical condition for capacity deterrence to be effective is that it has to be credible or not easily reversible (Dixit, 1979; Mazzeo, 2002). There are two ways that an incumbent can deploy capacity to threatened routes. The first way is to acquire aircrafts, through either purchase or leasing, from the market. To see if such acquisition is reversible, we collect industry data to assess the degree of capital commitment. We first observe that airlines spend large sums of money to purchase aircrafts that cannot be easily resold in a short period of time. Around $70 \%$ of the aircrafts operated by airlines are owned rather than leased during our sample period (International Air Transport Association, 2016); the ratio is even higher for established (incumbent) airlines (The Economist, 2012). In addition, we observe that even though airlines do lease some aircraft to maintain flexibility, especially during economic downturns, these leases are typically longterm agreements. Prior research notes that even operating leases in tight credit markets can last over 8 years (Gibson, 2008). In sum, due to the significant acquisition cost and long holding period, capacity acquired by airlines from the market is not easily reversible and therefore can serve as a commitment mechanism.

A second way that an incumbent airline can deploy capacity to threatened routes is via excess capacity resulting from random demand shocks (Lieberman, 1987a). We argue that excess capacity in different submarkets can be deployed to deter entry in a threatened submarket, and reversing such deployment is not easy in our setting for at least two reasons. First, airlines usually publish their flight schedule several quarters before the flying quarter, ${ }^{4}$ which causes rigidity in schedule reversal. Second, incumbent airlines operate on multiple heterogeneous routes. The occurrence of positive demand shocks on non-threatened routes is likely to be idiosyncratic. Therefore, the need for the

\footnotetext{
${ }^{3}$ Using actual cost data, we find that the unit operating cost per available seat mile (ASM) in 2013 was 13.89 cents for Delta and 11.06 cents for Southwest. The unit capital cost per ASM was 1.08 cents for Delta and 1.05 cents for Southwest, both less than $10 \%$ of their operating costs. Delta had a slightly higher average capital cost but a significantly lower capital cost relative to its operating cost.

${ }^{4}$ Consumers can book their tickets hundreds of days in advance with major airlines (https://thepointsguy.com/2017/11/howfar-in-advance-book-airfare/).
} 
incumbent to reverse capacity deployment is hard to predict, which makes reversal uncertain ex post and deployment for deterrence more credible ex ante. ${ }^{5}$

To some extent the issue of credible commitment is context-specific and subject to empirical examination. We therefore check industry reports and empirical studies on the airline industry to confirm the face validity of our arguments. There is a large number of complaints made by LCCs that FSC incumbents such as American Airlines and Air Canada aggressively expand capacity (by either adding flight frequencies or using larger aircrafts) when faced with the threat of LCC entry (Edlin \& Farrell, 2002; Lazar, 2000; Transportation Research Board National Research Council, 1999). Empirical evidence also suggests that the FSC incumbents' capacity expansion in threatened markets is consistent with an objective to deter entry: "By committing significant additional capacity to a particular market, a dominant national carrier is able to drive variable costs and fares to levels that often make the market unprofitable for an LCC competitor offering a much less attractive product to consumers" (Williams, 2013 p. 3).

Therefore, the airline industry satisfies the conditions for Proposition 1, which we can translate into the following hypothesis:

Hypothesis 1. Following the threat of entry from an LCC, an FSC incumbent will be more likely to increase its capacity on the threatened route than an LCC incumbent.

When firms operate in multiple submarkets, the fit of these submarkets to the firms' core strategy is likely to vary. Such variation in fit between an incumbent's market position and submarket characteristics provides differential opportunities for potential entry. While the existing literature suggests that submarkets that have a tighter fit with an incumbent's position pose greater costs of entry (Rivkin, 2000), our model explicates the "fit" with different types of interdependencies.

The degree of within-submarket demand substitutability gauges customers' tendency to switch between products. Proposition 2 states that a premium incumbent will be better off deterring than ignoring or accommodating a low-cost entrant when the threatened submarket comprises more substitutable customer segments. Intuitively, because customers who prefer a premium product to low price are unlikely to perceive the product offered by a low-cost entrant as a substitute, they are less likely to switch to the low-cost firm post entry. Accordingly, the low-cost firm will be more likely to stay away from submarkets where a larger proportion of potential customers demand premium products and will instead enter submarkets with more price-sensitive customers. Foreseeing that, the premium incumbent is expected to be less aggressive in entry deterrence in submarkets with predominantly premium customers.

In the airline industry, business travelers put more value on premium quality service and are less price sensitive than leisure travelers. On routes with a higher percentage of business travelers, an LCC is less likely to attract enough customers and is therefore less likely to enter. Accordingly, the FSC incumbent will be less likely to expand capacity in response to a threat of entry.

Hypothesis 2. Following the threat of entry from an LCC, an FSC incumbent will be less likely to increase its capacity on a threatened route that has a larger percentage of business travelers.

\footnotetext{
${ }^{5}$ To empirically examine the persistence of capacity utilization on individual routes, we examine the flight-level on-time performance database maintained by the Bureau of Transportation Statistics. We extract from the database the unique aircraft identifier associated with each flight. Based on the aircraft identifiers we find that during our sample period, an aircraft was flown on a specific route for an average of 36 months. In comparison, an aircraft was flown on a specific threatened route for an average of 51 months. This suggests a fairly high degree of capacity commitment at the route level.
} 
Between-submarket demand complementarity influences an incumbent's response in a different way. When a low-cost firm enters a submarket, the premium incumbent will lose customers in the contested submarket. However, the increased competition induced by entry also increases total demand in the contested submarket, thereby benefiting the incumbent's complementary and unthreatened submarkets. Proposition 3 states that a premium incumbent will be better off accommodating than deterring a low-cost entrant that offers a more complementary product or service. This is consistent with the empirical finding in the hotel industry that entry with a complementary (e.g., agglomeration) benefit to the incumbent faced a more accommodating response (McCann \& Vroom, 2010).

If a significant proportion of customers in the contested submarket also demand products or services from the incumbent in its unthreatened submarkets, then the incumbent has less incentive to deter entry in the contested submarket. An apt example in the airline context is domestic routes that connect to the incumbent's international hubs (that is, domestic airports with a large number of international flights operated by the FSC incumbent). Entry by an LCC into these routes is expected to increase the number of passengers who will connect to the incumbent's international flights (which LCCs do not serve) and increase the incumbent's joint profits on domestic and international flights. As a result, the FSC incumbent will be less aggressive in deterring entry.

Hypothesis 3. Following the threat of entry from an LCC, an FSC incumbent will be less likely to increase its capacity on a threatened route that connects to its international hubs.

\section{6 | EMPIRICAL DESIGN}

\subsection{Data and sample}

Theoretically, an incumbent can respond to a potential entrant using different competitive tools, such as price, capacity, and quality differentiation. In the airline industry, prior studies have found that from 1993 to 2004, incumbent carriers lowered their price and quality level in response to the threat of Southwest entry (Goolsbee \& Syverson, 2008; Prince \& Simon, 2015). We, therefore, first compared incumbent airlines' responses along these dimensions to ensure consistency with prior studies. We then investigated capacity response.

Our data come mainly from three sources. The first is the Origination and Destination Survey (DB1B) collected by the U.S. Bureau of Transportation Statistics (BTS). It is a 10\% random sample of airline tickets from reporting carriers, aggregated to the quarterly level to protect confidentiality. It has been used to study incumbents' price response to Southwest's entry threats (e.g., Goolsbee \& Syverson, 2008). The second data source is a survey of flight-level on-time performance collected by BTS. It has been used to study delays, though most prior studies sample only small parts of it (e.g., Forbes \& Lederman, 2010). The third data source is the OAG Scheduler, a commercial dataset that contains information about seat capacity on every flight. It has been used to study market entry, though again most prior studies sample only small parts of it (e.g., Berry \& Jia, 2010).

We drew data from these databases for the years between 2003 and 2012. We limited our study to the 11 major incumbent airlines that had the most complete data: six FSCs (American, Continental, Delta, Northwest, United, US Airways), and five LCCs (JetBlue, AirTran, ExpressJet, Midwest, 
T A B L E 1 Comparative statistics for FSCs, non-Southwest LCCs, and Southwest

\begin{tabular}{llll} 
& FSCs & LCCs & Southwest \\
Average ticket price $^{\mathrm{a}}$ & 199 & 159 & 137 \\
Average route distance $^{\mathrm{b}}$ & 905 & 647 & 812 \\
Number of passengers per route $^{\mathrm{b}}$ & 1,463 & 1,371 & 2,362 \\
Number of flights per route $^{\mathrm{b}}$ & 131 & 317 & 654 \\
Number of seats per route $^{\mathrm{c}}$ & 10,553 & 9,131 & 14,934 \\
Number of seats per aircraft $^{\mathrm{b}}$ & 170 & 100 & 137 \\
Scheduled flight time $^{\mathrm{b}}$ & 133 & 105 & 126 \\
Diff. between ramp to ramp and airtime per flight in minutes $^{\mathrm{b}}$ & 28 & 25 & 16 \\
Average load factor $^{\mathrm{b}}$ & 0.75 & 0.74 & 0.71 \\
Departure delay in minutes $^{\mathrm{c}}$ & 12.7 & 14.5 & 9.2 \\
\hline
\end{tabular}

${ }^{\mathrm{a}}$ Based on BTS DB1B data.

${ }^{\mathrm{b}}$ Based on BTS T100 data.

${ }^{\mathrm{c}}$ Based on BTS on-time performance data.

Alaska). ${ }^{6}$ Following prior studies, we restricted our study to non-stop flights between the 100 busiest airports (by enplanement) within the continental United States, which account for $85 \%$ of the total flights flown in the United States.

Table 1 compares the key operational statistics of FSCs, LCCs (excluding Southwest), and Southwest. It shows that Southwest charged the lowest price per route. It followed a consistent highdensity strategy, flying a large number of flights on a small number of routes and using only one type of aircraft (a Boeing 737 with 137 economy-class seats) to standardize its operations across routes. It enjoyed the fastest aircraft turnaround and had the shortest delays. Table 1 also reveals clear differences between FSCs and LCCs. FSCs flew longer routes, charged higher prices, had larger planes, and experienced shorter delays.

We followed Goolsbee and Syverson (2008) to identify routes facing an entry threat from Southwest. Figure 2 presents an illustration. In 2005, Southwest operated the route between Chicago Midway and Cleveland, as well as five routes from Philadelphia (to Hartford, Ft. Lauderdale, West Palm Beach, Raleigh/Durham, and Los Angeles, respectively). In October 2006, Southwest entered Washington Dulles with four new routes to Chicago Midway, Las Vegas, Tampa, and Orlando, respectively. Assume an incumbent airline was already flying the three routes from Washing Dulles to Cleveland, Hartford, and Philadelphia, respectively. Because Southwest already operated in Cleveland, Hartford, and Philadelphia, it would likely start to fly the three routes connecting Washington Dulles with these airports. These three routes were therefore "threatened" by Southwest's entry and were included in our sample.

We also followed prior studies (Goolsbee \& Syverson, 2008; Prince \& Simon, 2015) and examined incumbent responses several quarters (i.e., up to 3 years) before the entry threat. This is because the market is usually aware of an airport entry well before the date of entry. First, airlines often announce their entry into an airport several quarters before actually entering, in order to advertise

\footnotetext{
${ }^{6}$ There were some mergers among the sample firms. For example, Southwest acquired AirTran in 2010. However, in the BTS databases, the two carriers continued to report separately as of 2013, so we treated them as separate carriers. For other mergers, we treated the carriers as separate until they started to report as a combined carrier in the BTS databases. As a robustness check, we also treated them as one merged entity throughout the sample period (e.g., treating Northwest as Delta for the entire sample period). Results were similar.
} 


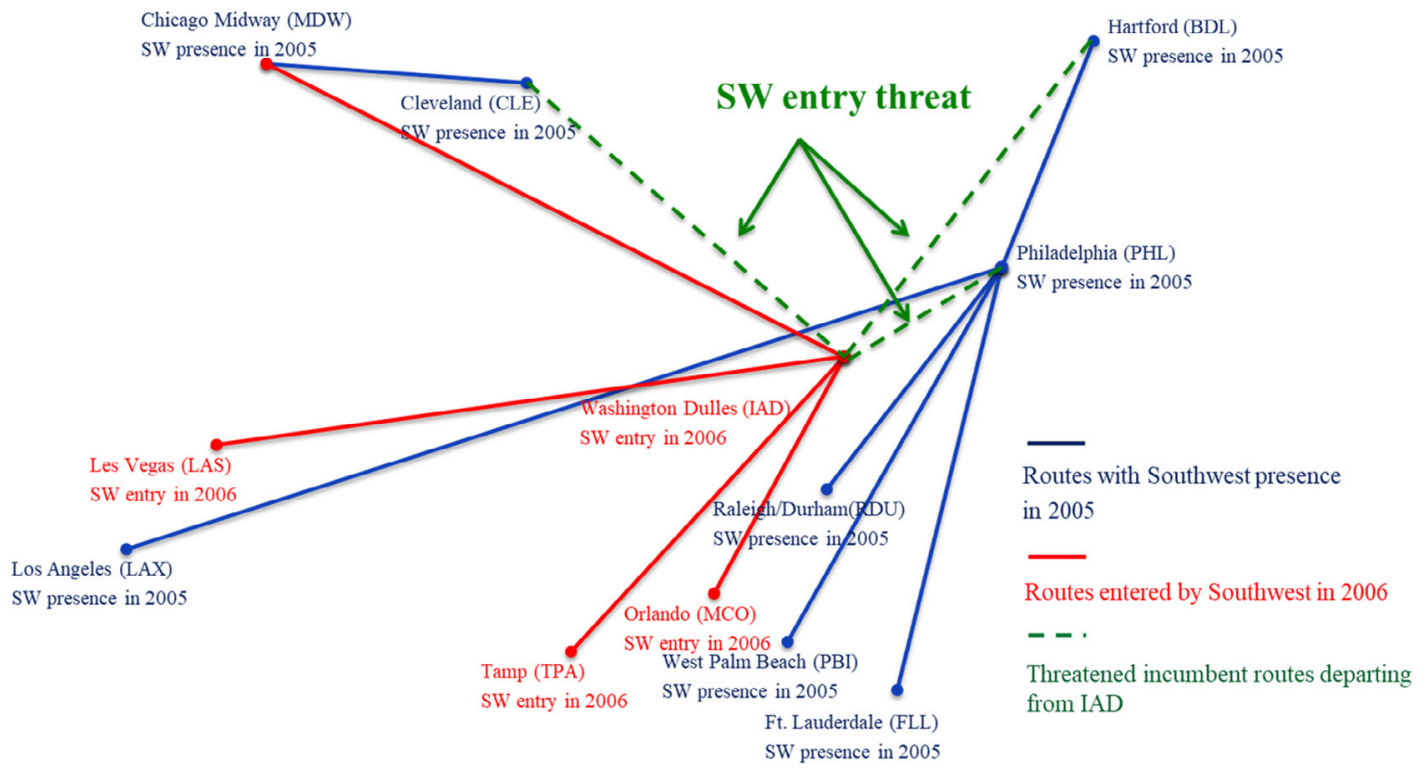

F I G U RE 2 Part of southwest route network in 2005 and 2006

and sell tickets, hire workers, etc. In the case of Washington Dulles, Southwest announced its entry 6 months before the first day of operation. In addition, information about future entry diffuses as the entrant starts to negotiate gate leases and invest in infrastructure at the target airport. For each threatened route, we followed prior studies and limited the sample period to the 25 -quarter window surrounding the quarter during which Southwest started operating in the second endpoint of the route. To focus attention on threatened rather than actual entry, we dropped routes in which Southwest started operating in the second endpoint and the threatened route at the same time.

For the remaining threatened routes, we constructed three samples. Sample 1 is an intersection set of the DB1B and OAG, aggregated to the carrier-route-quarter level. Because of the DB1B's 10\% reporting and quarterly aggregation rules, Sample 1 has only about 30,000 observations. We used Sample 1 to study price responses to compare to prior studies (e.g., Goolsbee \& Syverson, 2008). Sample 2 is an intersection set of the on-time performance and OAG databases, aggregated to the carrier-route-month level. Because of the smaller coverage of the on-time database, Sample 2 has about 70,000 observations. We used Sample 2 to study quality responses to compare to prior studies (e.g., Prince \& Simon, 2015). Sample 3 is the most comprehensive and our main sample. It is based on the OAG dataset and aggregated to the carrier-route-month level. It contains 88 airports, 1,264 routes, and about 120,000 observations. We used Sample 3 to test the hypotheses about capacity responses. Studying capacity responses on Samples 1 and 2 generated similar results.

\section{2 | Variables}

Our main dependent variable, SeatCapacity ${ }_{\text {rit }}$, is the total number of installed seats on flights flown by carrier $i$ on route $r$ (a directional origin-destination pair) at time $t$. We also examined other competitive instruments to compare with prior studies. Price $_{\text {rit }}$, is the quarterly average ticket price for all direct and round-trip flights. Departure Delay rit $_{\text {is }}$ the average minutes between scheduled and actual departure time. Because different carriers had different baseline values for these variables, we log- 
transformed the dependent variables to reduce value dispersion. The log transformation also made the estimated coefficients easier to interpret: They reflect percentage changes in the dependent variable with a unit change in the independent variable.

Our independent variables are a set of time dummies for periods including and surrounding the quarter when Southwest threatened a route and time dummies for periods including and after Southwest entered (started flying) the route. These dummies are mutually exclusive. Coefficients on these time dummies reflect the relative sizes of the dependent variable in each dummy period relative to its average value in the excluded period, that is, when all the time dummies assume a value of zero.

All regressions include carrier-route, carrier-time (quarter or month), and origin-airport-time (quarter or month) fixed effects. In the delay analysis, we also controlled for airport congestion. We first calculated congestion at the hourly level, which is the number of flights departing from or arriving at an airport during any given hour, divided by the maximum number of flights departing from or arriving at that airport in that hour at any point between 2003 and 2012. We then took the monthly average of that ratio.

Table 2 provides summary statistics for the sample routes. About $82 \%$ of the observations were for FSCs. On average, a carrier charged US\$181 $(\exp (5.20))$ for each ticket sold and flew 7,708 (exp (8.95)) seats on each route every month. An average flight was $9.5(\exp (2.25))$ minutes late at departure, which is similar to the results in prior studies of on-time performance (e.g., Forbes \& Lederman, 2010). The average airport operated at $50 \%$ of its maximum capacity.

\subsection{Specifications}

We first replicated prior studies on incumbent responses to Southwest's entry threats by using a similar specification (Goolsbee \& Syverson, 2008; Prince \& Simon, 2015). In the pricing analysis, because the DB1B pricing information is available only at the quarter level, we used a quarterly model.

T A B L E 2 Summary statistics for sample routes

\begin{tabular}{|c|c|c|c|c|c|c|c|c|c|c|}
\hline & Definition & Mean & $S D$ & Min & $\operatorname{Max}$ & (1) & (2) & (3) & (4) & (5) \\
\hline $\begin{array}{l}\text { (1) Quarter of SW } \\
\text { threat }\end{array}$ & $\begin{array}{l}\text { SW "threatens" the route } \\
\text { during the quarter }(1,0)\end{array}$ & 0.05 & 0.23 & 0 & 1 & 1.000 & & & & \\
\hline (2) Price & $\begin{array}{l}\text { Quarterly average ticket } \\
\text { price for all direct and } \\
\text { round-trip flights, logged }\end{array}$ & 5.20 & 0.41 & 2.37 & 7.24 & -0.007 & 1.000 & & & \\
\hline (3) Seat capacity & $\begin{array}{l}\text { Number of installed seats } \\
\text { flown, logged }\end{array}$ & 8.95 & 0.988 & 3.62 & 11.17 & -0.016 & -0.030 & 1.000 & & \\
\hline (4) Departure delay & $\begin{array}{l}\text { Time between scheduled } \\
\text { and actual departure time } \\
\text { in minutes, logged }\end{array}$ & 2.25 & 0.79 & -0.69 & 5.41 & -0.005 & -0.030 & 0.091 & 1.000 & \\
\hline (5) Congestion & $\begin{array}{l}\text { Number of flights passing } \\
\text { the origin airport divided } \\
\text { by the maximum number } \\
\text { of flights passing the } \\
\text { origin airport during the } \\
\text { sample period }\end{array}$ & 0.50 & 0.12 & 0.003 & 1 & 0.003 & 0.023 & -0.026 & 0.051 & 1.000 \\
\hline
\end{tabular}




$$
\begin{aligned}
\text { Price }_{r i t}= & \alpha_{r i}+\alpha_{i t}+\alpha_{\text {origin }, t}+\sum_{\tau=-10}^{2} \beta_{\tau}(\tau Q \text { before } / \text { after SW threat })_{r\left(Q_{\theta}+\tau \mathrm{Q}\right)} \\
& +\beta(3-12 Q \text { after SW threat })_{r t} \\
& +\sum_{\tau=0}^{2} \gamma_{\tau}(\tau Q \text { after SW entry })_{r\left(q_{e}+\tau \mathrm{Q}\right)} \\
& +\gamma(3-12 Q \text { after SW entry })_{r t}+\varepsilon_{r i t}
\end{aligned}
$$

where Price ${ }_{r i t}$ is defined as before. $Q_{\theta}$ is the quarter during which the route was threatened by Southwest (SW), and $Q_{e}$ is the quarter during which the route was entered. $\tau Q$ before/after $\mathrm{SW}$ threat are time dummies indicating that the current quarter is $\tau$ (from 1 to 10) quarters before or $\tau$ (from 0 to 2) quarters after SW's threat. $\tau Q$ after SW entry are time dummies that indicate that the current quarter is $\tau$ (from 0 to 2) quarters after SW's entry. $3-12 Q$ after SW threat and $3-12 Q$ after SW entry are time dummies that indicate that the current quarter is from 3 to 12 quarters after SW's threat and entry, respectively. Coefficients on the time dummies reflect the relative sizes of the dependent variable in each period relative to its average value in the excluded period, that is, the 12th and 11th quarters before the quarter of SW's threat. We clustered standard errors by route-carrier to account for serial correlation in the error terms.

In the capacity and quality analyses, we used specifications similar to Equation 1, except that the analyses were at the monthly rather than quarterly level.

After confirming that our results are qualitatively similar to those of prior studies, we simplified the specifications by collapsing the time dummies before SW's threat into one time dummy variable (1-10Q before SW threat), by collapsing the time dummies after SW's threat and before SW's actual entry into one time dummy (0-12Q after SW threat), and by collapsing the time dummies after SW's actual entry into one time dummy (0-12Q after SW entry).

We used different subsamples to capture heterogeneity in incumbent responses to Southwest's entry threats. To test Hypothesis 1, we separated the sample into threatened routes that were operated by FSC incumbents and those that were operated by LCC incumbents. To test Hypothesis 2, we separated the sample into FSCs' threatened routes that were expected to have a large number of business travelers and those that were expected to have a large number of leisure travelers. We used information provided by the Bureau of Economic Analysis and the Census Bureau about total personal income, total personal income coming from lodging and food services, and total number of business establishments in the county where an airport is located. We defined threatened routes that were expected to have a large number of non-business travelers as routes that either originated from or arrived at a county with an above-median percentage of personal income coming from lodging and food services but a below-median number of business establishments. ${ }^{7}$ We expect these routes to be destinations for price-sensitive leisure travelers, whereas other routes are more likely to attract business travelers. To test Hypothesis 3, we separated the sample into FSCs' threatened routes that connect to hubs that have a large number of international flights, routes that connect to hubs with few international flights, and non-hub routes.

${ }^{7}$ Using total employment of business establishments and average size of business establishments (measured using employment) generated similar results. 


\section{7 | RESULTS}

\subsection{FSC versus LCC incumbents' responses to entry threats}

Table 3 provides an overview of incumbents' responses to Southwest's entry threats using various competitive instruments. We first replicated the specifications from prior studies (Goolsbee \& Syverson, 2008; Prince \& Simon, 2015) that used data from an earlier time period (1993-2004). We separately estimated FSC and LCC responses. Columns 1 and 2 examine price responses. As in Goolsbee and Syverson (2008), we weighted observations by the average number of passengers flown by an incumbent carrier on the route to assess the "aggregate" responses and to mitigate high volatility on lowvolume routes. The coefficients show similar price responses from FSC and LCC incumbents in response to the threat of Southwest's entry. Neither responded significantly to the threat of entry, but both dropped their price by $12-20 \%$ after Southwest's actual entry. In general, our results on price responses are not as strong as those in prior studies. Perhaps this is because after a decade of price wars, in recent years price-cutting has become less feasible, or is seen as a less effective instrument (Berry \& Jia, 2010).

Columns 3 and 4 examine quality responses in terms of on-time performance. In line with prior studies (Prince \& Simon, 2015), we find that FSC incumbents experienced more delay in response to the threat of Southwest entry. In supplementary analyses, we observed that FSC incumbents reduced scheduled flight duration (i.e., reduced slack), which might have contributed to the deterioration in on-time performance. Again, LCCs did not experience a significant change in delay.

The last two columns of Table 3 examine seat capacity. The results show that FSCs increased their seat capacity in response to entry threat-by $26 \%$ by the quarter in which Southwest had threatened (but not entered) the route, by $35 \%$ by the quarter in which Southwest had entered the route, and by $41 \%$ by the end of the third year after Southwest's entry. In contrast, LCC incumbents reduced their seat capacity (to accommodate Southwest's entry), though these changes were mostly statistically insignificant. These results support Hypothesis 1. As we will discuss later in the "Additional robustness checks" subsection, we also observed that FSC incumbents increased flight frequencies. Note that an increase in seat (and flight) capacity coupled with a reduction in scheduled flight duration likely contributed to the increased delays for FSC flights that was observed in Column 3. At the same time, while the increase in delay and seat supply could lower price, the increased flight frequencies could also provide a closer match to consumers' preferred schedule, thereby increasing consumers' willingness to pay. These two opposite effects might explain the lack of significant price change in Column 1.

\subsection{1 | Alternative explanations}

We performed a few tests to ensure that our main results on incumbents' capacity responses are robust to alternative explanations. One alternative explanation is that the incumbent might have increased capacity in response to increased market demand rather than Southwest's (threatened or actual) entry. To completely address this alternative explanation, we need to include route-quarter/month fixed effects to capture any market and time specific local demand shocks. However, such fixed effects will be perfectly correlated with our threat and entry time dummies, which would prevent us from identifying any effect. As a compromise, in addition to route-carrier and carrier-quarter/month fixed effects that are controlled for in prior studies (e.g., Goolsbee \& Syverson, 2008), we included origin-time (in year/months) fixed effects. Collectively, these fixed effects account for unobservable time-invariant route-carrier specific factors, carrier-time specific factors, and origin airport-time specific factors that would influence capacity decisions. In addition, as a robustness check, Table 4 includes route-half-year fixed effects. 
T A B LE 3 An overview of responses to entry threats

\begin{tabular}{|c|c|c|c|c|c|c|}
\hline & \multicolumn{2}{|l|}{ Price } & \multicolumn{2}{|c|}{ Departure delay } & \multicolumn{2}{|l|}{ Seat capacity } \\
\hline & FSC & LCC & FSC & LCC & FSC & LCC \\
\hline $10 Q$ before $\mathrm{SW}$ threat & $0.075[0.001]$ & $0.017[0.417]$ & $0.047[0.194]$ & $-0.079[0.478]$ & $0.040[0.010]$ & $0.037[0.258]$ \\
\hline $9 Q$ before $\mathrm{SW}$ threat & $-0.025[0.200]$ & $0.010[0.722]$ & $0.141[0.000]$ & $0.070[0.467]$ & $0.147[0.000]$ & $-0.072[0.092]$ \\
\hline $8 Q$ before $\mathrm{SW}$ threat & $-0.045[0.023]$ & $0.005[0.847]$ & $0.099[0.008]$ & $0.06[0.526]$ & $0.141[0.000]$ & $-0.075[0.115]$ \\
\hline $7 Q$ before $\mathrm{SW}$ threat & $-0.031[0.117]$ & $0.034[0.399]$ & $0.048[0.212]$ & $0.111[0.319]$ & $0.131[0.000]$ & $-0.05[0.284]$ \\
\hline $6 Q$ before $\mathrm{SW}$ threat & $0.006[0.805]$ & $0.006[0.876]$ & $0.044[0.287]$ & $-0.071[0.503]$ & $0.160[0.000]$ & $-0.045[0.375]$ \\
\hline $5 Q$ before $\mathrm{SW}$ threat & $-0.007[0.772]$ & $-0.002[0.949]$ & $0.104[0.011]$ & $-0.017[0.874]$ & $0.185[0.000]$ & $-0.068[0.187]$ \\
\hline $4 Q$ before $\mathrm{SW}$ threat & $-0.012[0.633]$ & $-0.017[0.688]$ & $0.015[0.730]$ & $-0.097[0.437]$ & $0.218[0.000]$ & $-0.015[0.803]$ \\
\hline $3 Q$ before $\mathrm{SW}$ threat & $0.017[0.541]$ & $-0.028[0.540]$ & $0.017[0.715]$ & $0.068[0.590]$ & $0.247[0.000]$ & $-0.005[0.931]$ \\
\hline $2 Q$ before $\mathrm{SW}$ threat & $0.045[0.125]$ & $-0.018[0.690]$ & $0.043[0.381]$ & $-0.086[0.407]$ & $0.224[0.000]$ & $-0.002[0.974]$ \\
\hline $1 Q$ before $\mathrm{SW}$ threat & $0.035[0.252]$ & $-0.013[0.782]$ & $0.079[0.125]$ & $-0.094[0.419]$ & $0.248[0.000]$ & $0.018[0.796]$ \\
\hline Quarter of SW threat & $0.001[0.979]$ & $-0.038[0.431]$ & $0.108[0.042]$ & $-0.123[0.297]$ & $0.262[0.000]$ & $0.022[0.755]$ \\
\hline $1 Q$ after $\mathrm{SW}$ threat & $-0.003[0.932]$ & $-0.032[0.524]$ & $0.065[0.257]$ & $-0.035[0.789]$ & $0.266[0.000]$ & $0.075[0.318]$ \\
\hline $2 Q$ after SW threat & $0.020[0.595]$ & $-0.006[0.915]$ & $0.121[0.057]$ & $0.028[0.843]$ & $0.271[0.000]$ & $0.05[0.546]$ \\
\hline $3-12 Q$ after SW threat & $0.008[0.843]$ & $0.006[0.936]$ & $0.192[0.005]$ & $0.057[0.714]$ & $0.355[0.000]$ & $0.064[0.449]$ \\
\hline Quarter of SW entry & $-0.121[0.011]$ & $-0.031[0.694]$ & $0.184[0.012]$ & $-0.047[0.767]$ & $0.353[0.000]$ & $-0.041[0.661]$ \\
\hline $1 Q$ after SW entry & $-0.131[0.009]$ & $-0.175[0.026]$ & $0.196[0.011]$ & $0.002[0.989]$ & $0.392[0.000]$ & $0.038[0.682]$ \\
\hline $2 Q$ after SW entry & $-0.191[0.000]$ & $-0.169[0.038]$ & $0.206[0.007]$ & $-0.011[0.950]$ & $0.425[0.000]$ & $0.021[0.836]$ \\
\hline $3-12 Q$ after SW entry & $-0.133[0.009]$ & $-0.197[0.022]$ & $0.165[0.043]$ & $-0.154[0.403]$ & $0.411[0.000]$ & $-0.019[0.856]$ \\
\hline Congestion & & & $0.076[0.480]$ & $0.505[0.009]$ & & \\
\hline Carrier time FEs & Yes & Yes & Yes & Yes & Yes & Yes \\
\hline Origin time FEs & Yes & Yes & Yes & Yes & Yes & Yes \\
\hline Carrier route FEs & Yes & Yes & Yes & Yes & Yes & Yes \\
\hline Observations & 27,986 & 5,904 & 55,700 & 11,825 & 97,559 & 21,731 \\
\hline Adjusted $R^{2}$ & 0.580 & 0.770 & 0.554 & 0.532 & 0.876 & 0.871 \\
\hline
\end{tabular}

Time reflects each year-quarter pair in price estimations and each year-month pair in quality and capacity estimations. Robust standard errors are clustered at the carrier-route level. $p$-values are included in square brackets.

Compared with the results in the last two columns of Table 3, the first two columns of Table 4 show smaller but similar effects.

Moreover, if all participants were just responding to increasing demand in the market, we should see Southwest enter rather than avoid routes where incumbents had increased capacity. In the last four columns of Table 4, we separated the threatened routes into those that Southwest entered within 3 years after the threat and those that Southwest did not enter within 3 years after the threat. Results show that Southwest did not enter routes where the FSC incumbent had significantly increased capacity. Instead, it entered routes where the FSC incumbent had not significantly increased capacity. These results contradict the alternative explanation of a common response to market demand.

Results in Tables 3 and 4 also support our arguments that capacity expansion can be used as a credible commitment by incumbents in the airline industry. For example, Table 3 shows that, after controlling for route-specific demand shocks, the FSC incumbent maintained the increased level of capacity over a long-period (i.e., 3 years) after entry threat, even after Southwest's entry. If the incumbent were not committed, it would have scaled back its capacity after Southwest's entry. Table 4 provides additional evidence that Southwest did take capacity expansion by the incumbent 
T A B L E 4 Seat capacity responses: Robustness checks with route-half-year fixed effects

\begin{tabular}{|c|c|c|c|c|c|c|}
\hline & \multicolumn{2}{|l|}{ All routes } & \multicolumn{2}{|c|}{$\begin{array}{l}\text { Routes not entered within } \\
12 Q \text { after threat }\end{array}$} & \multicolumn{2}{|c|}{$\begin{array}{l}\text { Routes entered within } \\
12 Q \text { after threat }\end{array}$} \\
\hline & $\overline{\text { FSC }}$ & LCC & FSC & $\mathrm{LCC}$ & FSC & LCC \\
\hline $10 Q$ before $\mathrm{SW}$ threat & $0.023[0.288]$ & $0.041[0.345]$ & $0.034[0.173]$ & $0.036[0.486]$ & $-0.074[0.412]$ & $0.05[0.669]$ \\
\hline $9 Q$ before $\mathrm{SW}$ threat & $0.110[0.002]$ & $-0.047[0.529]$ & $0.114[0.007]$ & $-0.102[0.328]$ & $0.053[0.608]$ & $-0.114[0.554]$ \\
\hline $8 Q$ before $\mathrm{SW}$ threat & $0.120[0.003]$ & $0.002[0.987]$ & $0.133[0.007]$ & $-0.2[0.160]$ & $0.068[0.465]$ & $-0.146[0.567]$ \\
\hline $7 Q$ before $\mathrm{SW}$ threat & $0.125[0.015]$ & $0.077[0.444]$ & $0.126[0.036]$ & $-0.307[0.031]$ & $0.117[0.285]$ & $-0.102[0.694]$ \\
\hline $6 Q$ before $\mathrm{SW}$ threat & $0.159[0.005]$ & $0.108[0.343]$ & $0.168[0.014]$ & $-0.239[0.114]$ & $0.116[0.303]$ & $-0.239[0.464]$ \\
\hline $5 Q$ before $\mathrm{SW}$ threat & $0.195[0.001]$ & $0.058[0.639]$ & $0.225[0.003]$ & $-0.251[0.143]$ & $0.093[0.439]$ & $-0.163[0.610]$ \\
\hline $4 Q$ before $\mathrm{SW}$ threat & $0.238[0.000]$ & $0.081[0.574]$ & $0.295[0.000]$ & $-0.18[0.343]$ & $0.103[0.434]$ & $-0.214[0.588]$ \\
\hline $3 Q$ before $\mathrm{SW}$ threat & $0.259[0.000]$ & $0.167[0.277]$ & $0.321[0.000]$ & $-0.141[0.532]$ & $0.134[0.324]$ & $-0.158[0.685]$ \\
\hline $2 Q$ before $\mathrm{SW}$ threat & $0.207[0.006]$ & $0.238[0.140]$ & $0.264[0.007]$ & $-0.02[0.932]$ & $0.081[0.572]$ & $-0.191[0.660]$ \\
\hline $1 Q$ before $\mathrm{SW}$ threat & $0.222[0.005]$ & $0.249[0.151]$ & $0.306[0.004]$ & $0.01[0.971]$ & $0.074[0.631]$ & $-0.237[0.600]$ \\
\hline Quarter of SW threat & $0.235[0.005]$ & $0.259[0.171]$ & $0.332[0.003]$ & $-0.004[0.988]$ & $0.05[0.760]$ & $-0.358[0.491]$ \\
\hline $1 Q$ after $\mathrm{SW}$ threat & $0.233[0.007]$ & $0.305[0.128]$ & $0.320[0.006]$ & $-0.13[0.670]$ & $0.018[0.915]$ & $-0.027[0.959]$ \\
\hline $2 Q$ after $\mathrm{SW}$ threat & $0.222[0.014]$ & $0.3[0.167]$ & $0.317[0.010]$ & $-0.117[0.738]$ & $0.022[0.905]$ & $0.001[0.998]$ \\
\hline $3-12 Q$ after $\mathrm{SW}$ threat & $\mathrm{t} 0.272[0.005]$ & $0.239[0.310]$ & $0.382[0.004]$ & $-0.206[0.572]$ & $0.062[0.747]$ & $-0.16[0.770]$ \\
\hline Quarter of SW entry & $0.252[0.008]$ & $0.157[0.506]$ & & & $0.06[0.745]$ & $-0.278[0.612]$ \\
\hline $1 Q$ after SW entry & $0.351[0.001]$ & $0.091[0.709]$ & & & $0.127[0.516]$ & $-0.311[0.577]$ \\
\hline $2 Q$ after SW entry & $0.398[0.000]$ & $0.055[0.829]$ & & & $0.126[0.531]$ & $-0.269[0.635]$ \\
\hline $3-12 Q$ after SW entry & $0.395[0.001]$ & $-0.093[0.742]$ & & & $0.154[0.470]$ & $-0.407[0.503]$ \\
\hline Carrier time FEs & Yes & Yes & Yes & Yes & Yes & Yes \\
\hline Origin time FEs & Yes & Yes & Yes & Yes & Yes & Yes \\
\hline Carrier route FEs & Yes & Yes & Yes & Yes & Yes & Yes \\
\hline Route half-year FEs & Yes & Yes & Yes & Yes & Yes & Yes \\
\hline Observations & 97,540 & 21,692 & 73,101 & 11,288 & 22,532 & 8,257 \\
\hline Adjusted $R^{2}$ & 0.915 & 0.915 & 0.900 & 0.932 & 0.945 & 0.899 \\
\hline
\end{tabular}

Time reflects each year-quarter pair in price estimations and each year-month pair in quality and capacity estimations. Robust standard errors are clustered at the carrier-route level. $p$-values are included in square brackets.

as a credible commitment and avoided threatened routes where the incumbent had increased capacity.

A second alternative explanation is that there might be multiple incumbents operating on the same route, and they were just responding to each other's competitive moves rather than to Southwest's entry threat. To address this concern, in the first four columns of Table 5, we separated the threatened routes into three groups, those with only FSC incumbents, those with only LCC incumbents, and those with both types of incumbents. We aggregated the quarterly dummies to longer time dummies to save space. The results show that FSC incumbents increased their capacity mainly on threatened routes operated by only FSC incumbents (by $22 \%$ within 12 quarters of the threat). There was no significant response on other threatened routes where only LCCs operated or both FSCs and LCCs operated. ${ }^{8}$ This supports our argument that FSC incumbents were responding to Southwest's entry threat.

\footnotetext{
${ }^{8}$ As a robustness check, we also examined a much smaller number of routes with only one incumbent (FSC or LCC); results were similar.
} 
T A B LE 5 Seat capacity responses with heterogeneous incumbents and multimarket contact

\begin{tabular}{|c|c|c|c|c|c|c|}
\hline & \multirow{2}{*}{$\frac{\text { FSC-only }}{\text { Routes }}$} & \multirow{2}{*}{$\frac{\text { LCC-only }}{\text { Routes }}$} & \multicolumn{2}{|c|}{ Both-type routes } & \multicolumn{2}{|l|}{ All routes } \\
\hline & & & FSC & LCC & FSC & LCC \\
\hline $\begin{array}{c}1-10 Q \text { before } \\
\text { SW threat }\end{array}$ & $\begin{array}{c}0.171(0.029) \\
{[0.000]}\end{array}$ & $\begin{array}{c}-0.051(0.081) \\
{[0.527]}\end{array}$ & $\begin{array}{c}0.033(0.031) \\
{[0.285]}\end{array}$ & $\begin{array}{c}-0.004(0.049) \\
{[0.930]}\end{array}$ & $\begin{array}{c}0.211(0.033) \\
{[0.000]}\end{array}$ & $\begin{array}{c}0.035(0.073) \\
{[0.633]}\end{array}$ \\
\hline $\begin{array}{r}0-12 Q \text { after } \\
\text { SW threat }\end{array}$ & $\begin{array}{c}0.222(0.034) \\
{[0.000]}\end{array}$ & $\begin{array}{c}0.064(0.200) \\
{[0.751]}\end{array}$ & $\begin{array}{c}0.014(0.036) \\
{[0.704]}\end{array}$ & $\begin{array}{c}0.036(0.060) \\
{[0.548]}\end{array}$ & $\begin{array}{c}0.301(0.044) \\
{[0.000]}\end{array}$ & $\begin{array}{c}0.103(0.089) \\
{[0.248]}\end{array}$ \\
\hline $\begin{array}{r}0-12 Q \text { after } \\
\text { SW entry }\end{array}$ & $\begin{array}{c}0.244(0.055) \\
{[0.000]}\end{array}$ & $\begin{array}{c}-0.271(0.381) \\
{[0.480]}\end{array}$ & $\begin{array}{c}0.050(0.052) \\
{[0.336]}\end{array}$ & $\begin{array}{c}-0.018(0.069) \\
{[0.792]}\end{array}$ & $\begin{array}{c}0.408(0.085) \\
{[0.000]}\end{array}$ & $\begin{array}{c}0.308(0.108) \\
{[0.004]}\end{array}$ \\
\hline $\begin{array}{l}\text { Multimarket } \\
\text { contact } \\
\text { (MMC) }\end{array}$ & & & & & $\begin{array}{c}-36.489 \\
(44.128) \\
{[0.408]}\end{array}$ & $\begin{array}{l}27.225 \\
\quad(10.112) \\
{[0.007]}\end{array}$ \\
\hline $\begin{array}{l}\text { 1-10Q before } \\
\text { SW } \\
\text { threat*MMC }\end{array}$ & & & & & $\begin{array}{c}-1.911(0.389) \\
{[0.000]}\end{array}$ & $\begin{array}{r}-0.887 \\
(0.797) \\
{[0.266]}\end{array}$ \\
\hline $\begin{array}{l}\text { 0-12Q after } \\
\text { SW } \\
\text { threat*MMC }\end{array}$ & & & & & $\begin{array}{c}-2.870(0.549) \\
{[0.000]}\end{array}$ & $\begin{array}{r}-1.094 \\
(0.881) \\
{[0.215]}\end{array}$ \\
\hline $\begin{array}{l}\text { 0-12Q after } \\
\text { SW } \\
\text { entry*MMC }\end{array}$ & & & & & $\begin{array}{c}-3.803(0.799) \\
{[0.000]}\end{array}$ & $\begin{array}{r}-2.471 \\
(1.004) \\
{[0.014]}\end{array}$ \\
\hline $\begin{array}{l}\text { Carrier time } \\
\text { FEs }\end{array}$ & Yes & Yes & Yes & Yes & Yes & Yes \\
\hline $\begin{array}{l}\text { Origin time } \\
\text { FEs }\end{array}$ & Yes & Yes & Yes & Yes & Yes & Yes \\
\hline $\begin{array}{l}\text { Carrier route } \\
\text { FEs }\end{array}$ & Yes & Yes & Yes & Yes & Yes & Yes \\
\hline Observations & 60,951 & 3,031 & 34,756 & 17,165 & 97,559 & 21,731 \\
\hline Adjusted $R^{2}$ & 0.850 & 0.715 & 0.894 & 0.883 & 0.876 & 0.872 \\
\hline
\end{tabular}

Robust standard errors clustered at the carrier-route level are included in parentheses. $p$-values are included in square brackets.

A third alternative explanation is that LCCs are more likely to have overlapping operations with Southwest across their route networks. Such multimarket contact could create mutual forbearance and soften LCC incumbents' competitive interaction with Southwest. To address this possibility, we added multimarket contact and its interactions in the last two columns of Table 5. We followed Gimeno and Woo (1999) to sum the number of routes outside the focal route where the incumbent and Southwest competed. We normalized the sum with the total number of routes the incumbent operated, though results are similar if we take the sum without normalizing it. On average, an FSC incumbent shared 89 routes or $7 \%$ of its route network with Southwest, whereas an LCC incumbent shared 35 routes or $10 \%$ of its route network with Southwest. Coefficients in the last two columns of Table 5 suggest that multimarket contact, on average, did not influence an FSC incumbent's capacity decision on a route, but it did dampen the FSC incumbent's capacity responses to both threatened and actual entry from Southwest. In contrast, multimarket contact on average was positively correlated with an LCC incumbent's capacity decision on a route, but it dampens the LCC incumbent's 
T A B L E 6 Seat capacity responses on leisure versus business routes

\begin{tabular}{|c|c|c|c|c|}
\hline & \multicolumn{2}{|l|}{ Business routes } & \multicolumn{2}{|l|}{ Leisure routes } \\
\hline & FSC & $\mathrm{LCC}$ & FSC & $\mathbf{L C C}$ \\
\hline $\begin{array}{l}1-10 Q \text { before } \mathrm{SW} \\
\text { threat }\end{array}$ & $-0.057(0.080)[0.475]$ & $0.015(0.059)$ [0.803] & $0.086(0.021)[0.000]$ & $-0.038(0.045)$ [0.399] \\
\hline $\begin{array}{l}0-12 Q \text { after } \mathrm{SW} \\
\text { threat }\end{array}$ & $0.004(0.089)$ [0.965] & $0.202(0.133)[0.133]$ & $0.095(0.025)[0.000]$ & $-0.008(0.051)$ [0.877] \\
\hline $\begin{array}{l}0-12 Q \text { after SW } \\
\text { entry }\end{array}$ & $0.105(0.103)[0.311]$ & $-0.055(0.209)[0.791]$ & $0.097(0.041)$ [0.017] & $-0.016(0.065)[0.804]$ \\
\hline Carrier time FEs & Yes & Yes & Yes & Yes \\
\hline Origin time FEs & Yes & Yes & Yes & Yes \\
\hline Carrier route FEs & Yes & Yes & Yes & Yes \\
\hline Observations & 21,239 & 3,322 & 75,919 & 17,277 \\
\hline Adjusted $R^{2}$ & 0.867 & 0.898 & 0.883 & 0.872 \\
\hline
\end{tabular}

Robust standard errors clustered at the carrier-route level are included in parentheses. $p$-values are included in square brackets.

capacity responses to actual (not threatened) entry from Southwest. After controlling for multimarket contact, the coefficients of threat and entry time dummies remain similar.

\section{2 | Substitution within submarkets}

Table 6 compares the incumbent's capacity responses on threatened routes split by the expected presence of business and leisure travelers. The results show that the FSC incumbent's capacity responses were concentrated mostly on routes with leisure travelers (by $10 \%$ within 12 quarters of the threat). On routes that expected a large number of business travelers, the FSC incumbent hardly responded to threatened or even actual entry by Southwest. These results support Hypothesis 2. In comparison, LCC incumbents did not respond on either type of routes.

\section{3 | Complementarity across markets}

Table 7 compares FSC incumbents' capacity responses on their hub- and non-hub routes. The results show that FSC incumbents responded aggressively on their non-hub routes (increasing capacity by $19 \%$ within 12 quarters after Southwest's threat of entry) and on routes that connected to their exclusive domestic hubs-hubs not shared with other airlines (16\% within 12 quarters after Southwest's threat of entry). These results are consistent with Hypotheses 1 and 2: FSC incumbents deter more aggressively where the cost of capacity expansion is expected to be sufficiently low relative to operating cost (e.g., domestic hubs) and where the entrants are more likely to offer directly substitutable products (e.g., non-hub routes).

However, on threatened routes where the entrant might bring about demand that is complementary to demand in the incumbent's other routes-routes connecting to the incumbent's international hubs-we do not observe significant capacity response from FSC incumbents to entry threat. Thus, Hypothesis 3 is supported. 
T A B L E 7 FSCs' seat capacity responses on hub versus non-hub routes

\begin{tabular}{lllll} 
& $\begin{array}{l}\text { Incumbent hub } \\
\text { routes }\end{array}$ & $\begin{array}{l}\text { Incumbent } \\
\text { international } \\
\text { hub routes }\end{array}$ & $\begin{array}{l}\text { Incumbent-exclusive } \\
\text { domestic hub } \\
\text { routes }\end{array}$ & $\begin{array}{l}\text { Incumbent non-hub } \\
\text { routes }\end{array}$ \\
\hline $1-10 Q$ before SW threat & $0.031(0.031)[0.321]$ & $0.041(0.032)[0.203]$ & $0.120(0.042)[0.005]$ & $0.157(0.025)[0.000]$ \\
$0-12 Q$ after SW threat & $0.034(0.034)[0.317]$ & $0.043(0.035)[0.215]$ & $0.157(0.050)[0.002]$ & $0.192(0.031)[0.000]$ \\
$0-12 Q$ after SW entry & $0.116(0.054)[0.033]$ & $0.136(0.056)[0.015]$ & $0.161(0.063)[0.011]$ & $0.231(0.048)[0.000]$ \\
Carrier time FEs & Yes & Yes & Yes & Yes \\
Carrier time FEs & Yes & Yes & Yes & Yes \\
Carrier route FEs & Yes & Yes & Yes & Yes \\
Observations & 35,279 & 33,091 & 18,393 & 62,082 \\
Adjusted $R^{2}$ & 0.913 & 0.914 & 0.920 & 0.855 \\
\hline
\end{tabular}

Robust standard errors clustered at the carrier-route level are included in parentheses. $p$-values are included in square brackets.

\section{4 | Additional robustness checks}

We ran a battery of supplementary analyses to check the robustness of our results. These additional analyses are not included in the paper due to space limit but are available from the authors. First, to make sure these results are not influenced by market size, we excluded carrier-route pairs where the number of passengers in a quarter was less than 200 (Williams, 2013). The results were similar. We also removed markets for which the airline tickets were either less than $\$ 25$ or more than $\$ 2,500$, as such prices are likely due to typographical errors or special deals (Williams, 2013). The results were similar.

Second, change in seat capacity can be due to either a change in the number of flights or a change in plane capacity. To disentangle the two, we separately estimated the number of flights and seats per flight. Results were similar except that on incumbent-exclusive domestic hub routes, FSC incumbents increased capacity mainly by using larger planes rather than more frequent flights, probably due to congestion and availability of larger planes at the hubs. On non-hub routes, FSC incumbents increased capacity by using both more frequent flights and larger planes.

Third, it is possible that the FSC incumbents were responding to indirect competition from Southwest rather than the threat of entry. For example, in Figure 2, after Southwest entered Washington Dulles (having already been operating in Chicago Midway and Cleveland), customers might switch to flying Southwest flights from Washington Dulles to Cleveland via Chicago Midway rather than flying incumbent flights directly from Washington Dulles to Cleveland. We argue that even if the customers ignore the inconvenience of airport wait times, they are likely to fly the indirect flights only if Southwest flights on the two legs were competitively cheaper than the incumbent's direct flight. The descriptive statistics in Table 1 show that while Southwest's average ticket price of $\$ 137$ was lower than the FSCs' average ticket price of $\$ 199$, it was not cheaper to fly two Southwest flights than it was to fly one FSC flight. This undercuts the indirect competition argument. Nevertheless, we sought to re-estimate the results using a subsample of data excluding all threatened entries that closed a tripartite network. This subsample avoids the indirect competition problem. Unfortunately, excluding entries that closed a tripartite network resulted in too small of a sample, and our estimated models failed to converge in the presence of fixed effects. 


\section{8 | DISCUSSION}

The main objective of this study is to examine the impact of market positions and submarket interdependencies on competitive interactions between firms. Employing route-level data in the airline industry, we compared the responses of FSC incumbents and the responses of LCC incumbents, and the responses of FSC incumbents across their different submarkets, to entry threat from Southwest Airlines. Our empirical results support predictions from our formal model and indicate a few broad empirical patterns. First, competitive responses vary by market position. FSC incumbents expanded capacity, while LCC incumbents did not respond significantly. Second, significant variation in competitive responses exists even within an incumbent across its submarkets. This variation in responses correlated with differences in submarket interdependencies. FSC incumbents expanded capacity less aggressively in threatened submarkets that had less substitutable customer segments and in threatened submarkets that were more complementary with their unthreatened submarkets.

These results connect the research on entry deterrence in industrial organization with the research on market positions in strategic management. Specifically, we show that that incumbent firms' past choices of market positions and submarket interdependencies influence their competitive behavior. These past choices provide two sources of positional immutability: While one set of past choices (e.g., those about submarket interdependencies) generate barriers that prevent firms from a different position to imitate and enter, another set of past choices (e.g., those about products and costs) generate position-specific incentives that encourage a tough defense by the incumbent, thereby deterring entry. We see our effort to both formalize the empirical analyses and operationalize the theoretical model as crucial to understanding the conditions and mechanisms that drive the variation in entry deterrence decisions across different incumbents or across different submarkets for the same incumbent. For example, while research in industrial organization often assumes that the lower operating cost offers a competitive advantage in market entry, our results suggest that the marginal capacity investment cost of the incumbent is an important signal that the potential entrant should pay attention to. For another example, while prior studies have argued that strategic (positional) similarity leads to greater rivalry, our results suggest that this claim might be contingent upon specific tradeoffs an incumbent faces among ignoring, deterring, and accommodating entry.

Our findings also enrich the competitive dynamics literature in strategy. They imply that by strategically exploiting or avoiding submarket interdependencies, firms can employ a unique set of tools to manage competitive interaction. More generally, strong complementarities across submarkets reduce the need for costly deterrence. In contrast, markets with strong substitution across customer segments pose greater risks for incumbents that in turn necessitate deterrence. Therefore our study provides a more nuanced answer to the question of positional immutability. We show that competitive interaction between firms within or across market positions can be influenced by the nature of interdependencies across submarkets. This helps to reconcile the observed empirical patterns of competitive interaction which include both deterrence and accommodation responses by the same firm across submarkets.

Finally, this paper extends recent empirical work on entry deterrence in a few ways. By studying incumbent response to the threat of entry (rather than actual entry), this study mitigates the concern of endogeneity between incumbent response and entry. In addition, empirical studies of the airline industry for the previous decade (from late 1990s to the early 2000s) have concluded that FSC incumbents reduced prices in response to the threat of Southwest entry (Goolsbee \& Syverson, 2008) and saw their service quality (in terms of on-time performance) deteriorate as a consequence (Prince \& Simon, 2015). Our results show that, after these earlier episodes of price wars, during the 
more recent decade (2003-2012), FSC incumbents used capacity expansion as a major entry deterrence tool. By empirically examining a broad range of competitive responses, such as price and quality differentiation, in addition to capacity, we offer a comparison with the results in prior studies and a more coherent analysis of competitive responses to entry threat than prior studies.

A main limitation of our study is that it is based on data from one industry with its own idiosyncratic characteristics, which could potentially affect the generalizability of the study. We offer two speculations about generalizability. First, Southwest represents a particularly strong low-cost competitor. The fact that the entry threat of a low-cost leader triggers different responses from premium and low-cost incumbents presents important fodder for future research.

Second, the airline industry is unique in the sense that it is evolving toward a situation where the majority of customers in the industry are becoming increasingly price sensitive and less willing to pay for differentiation. A recent editorial on Bloomberg View described airline customers' willingness to pay as follows:

Ultimately, the reason airlines cram us into tiny seats and upcharge for everything is that we're out there on Expedia and Kayak, shopping on exactly one dimension: the price of the flight. To win business, airlines have to deliver the absolute lowest fare. And the way to do that is. .... to cram us into tiny seats and upcharge for everything. If American consumers were willing to pay more for a better experience, they'd deliver it. We're not, and they don't. (McCardle, 2015)

It is certainly possible that price differences between FSCs and LCCs are narrowing over time, and this in turn is reducing the differentiation advantage for FSCs. Market leaders in other contexts (e.g., boat racing as studied by Ross \& Sharapov, 2015) have also been found to imitate their followers' courses of action - thereby reducing differentiation - to stay ahead of competition. That said, there continue to be important differences between the strategies of FSCs and LCCs that we document in Table 1. Further, strategies such as hub-spoke networks, connecting flights, frequent traveler programs, and airline lounges continue to be important differentiators for FSCs. In sum, we believe that generalizability is an issue in this study as it is in any single-industry study. Replication across industries is necessary before we can attempt to extend the implications of our study to a broader range of industry contexts.

In conclusion, this paper highlights the impact of interdependencies on firms' competitive responses to entry threats. Despite being a single-industry study, it directs our attention to an understudied question in strategy: how market positions and submarket interdependencies influence interfirm competitive interactions. We have taken great care to document and explain our methodology to enable replication across industries. We hope this effort spurs more formal and empirical studies of competitive interaction.

\section{ACKNOWLEDGEMENTS}

We gratefully acknowledge the thoughtful suggestions provided by Editor Connie Helfat and two reviewers. We thank James Ostler, as well as seminar participants at City University of London, Erasmus University, HEC Paris, INSEAD, Purdue University, University of Kansas, and University of Michigan for helpful comments. We also thank Joe Mahoney for suggesting the title. Yiran Xie and Xindie Huang provided excellent research assistance. All errors remain ours. 


\section{REFERENCES}

Berry, S., \& Jia, P. (2010). Tracing the woes: An empirical analysis of the airline industry. American Economic Journal: Microeconomics, 2(3), 1-43.

Brander, J. A., \& Eaton, J. (1984). Product line rivalry. American Economic Review, 74(3), 323-334.

Chen, M.-J., \& Miller, D. (2012). Competitive dynamics: Themes, trends, and a prospective research platform. Academy of Management Annals, 6(1), 135-210.

Chen, M.-J., \& Miller, D. (2015). Reconceptualizing competitive dynamics: A multidimensional framework. Strategic Management Journal, 36(5), 758-775.

Ciliberto, F., \& Tamer, E. T. (2009). Market structure and multiple equilibria in the airline markets. Econometrica, 77 (6), 1791-1828.

Conlin, M., \& Kadiyali, V. (2006). Entry-deterring capacity in the Texas lodging industry. Journal of Economics \& Management Strategy, 15(1), 167-185.

Dixit, A. (1979). A model of duopoly suggesting a theory of entry barriers. Bell Journal of Economics, 10(1), $20-32$.

Dixit, A. (1980). The role of investment in entry-deterrence. Economic Journal, 90(357), 95.

Edlin, A. \& Farrell, J. (2002). The American Airlines case: A chance to clarify predation policy. Unpublished manuscript.

Ellison, G., \& Ellison, S. F. (2011). Strategic entry deterrence and the behavior of pharmaceutical incumbents prior to patent expiration. American Economic Journal: Microeconomics, 3(1), 1-36.

Forbes, S. J., \& Lederman, M. (2010). Does vertical integration affect firm performance? Evidence from the airline industry. Rand Journal of Economics, 41(4), 765-790.

Ghemawat, P., \& Levinthal, D. (2008). Choice interactions and business strategy. Management Science, 54(9), 1638-1651.

Gibson, W. (2008). Aircraft lessor prospects and lease valuation for airlines. Washington, DC: IATA and Airbusiness Academy.

Gimeno, J., \& Woo, C. Y. (1996). Hypercompetition in a multimarket environment: The role of strategic similarity and multimarket contact in competitive de-escalation. Organization Science, 7(3), 322-341.

Gimeno, J., \& Woo, C. Y. (1999). Multimarket contact, economies of scope, and firm performance. Academy of Management Journal, 42(3), 239-259.

Goolsbee, A., \& Syverson, C. (2008). How do incumbents respond to the threat of entry? Evidence from the major airlines. Quarterly Journal of Economics, 123(4), 1611-1633.

International Air Transport Association. (2016). IATA economics' chart of the week. Montreal, Canada: International Air Transport Association.

Joskow, A. S., Werden, G. J., \& Johnson, R. L. (1994). Entry, exit, and performance in airline markets. International Journal of Industrial Organization, 12(4), 457-471.

Kadiyali, V. (1996). Entry, its deterrence, and its accommodation: A study of the U.S. photographic film industry. RAND Journal of Economics, 27(3), 452-478.

Lazar, F. (2000). Why an air Canada monopoly is bad for air business. Canadian Business Economics, 8(1), 62-63.

Lieberman, M. B. (1987a). Excess capacity as a barrier to entry: An empirical appraisal. Journal of Industrial Economics, 35(4), 607.

Lieberman, M. B. (1987b). Postentry investment and market structure in the chemical processing industries. $R A N D$ Journal of Economics, 18(4), 533-549.

Lieberman, M. B., \& Demeester, L. (1999). Inventory reduction and productivity growth: Linkages in the Japanese automotive industry. Management Science, 45(4), 466-485.

McArdle, M. (2015). Hate to fly? It's your fault. Bloomberg. New York, NY: Bloomberg.

Makadok, R., \& Ross, D. G. (2018). Losing by winning: The danger zone of adverse competitor replacement. Strategic Management Journal, 39(7), 1990-2013.

Mazzeo, M. J. (2002). Competitive outcomes in product-differentiated oligopoly. Review of Economics and Statistics, 84(4), 716-728.

McCann, B. T., \& Vroom, G. (2010). Pricing response to entry and agglomeration effects. Strategic Management Journal, 31(3), 284-305.

Menon, A. R., \& Yao, D. A. (2017). Elevating repositioning costs: Strategy dynamics and competitive interactions. Strategic Management Journal, 38(10), 1953-1963. 
Milgrom, P., \& Roberts, J. (1982). Limit pricing and entry under incomplete information: An equilibrium analysis. Econometrica, 50(2), 443-459.

Morrison, S. A. (2001). Actual, adjacent, and potential competition: Estimating the full effect of Southwest Airlines. Journal of Transport Economics and Policy, 35(2), 239-256.

Mueller, K., \& Hüschelrath, K. (2012). Low cost carriers and the evolution of the U.S. airline industry. Competition and Regulation in Network Industries, 13(2), 133-159.

Pauwels, K., \& Srinivasan, S. (2004). Who benefits from store brand entry? Marketing Science, 23(3), 364-390.

Porter, M. E. (1980). Competitive strategy. New York, NY: Free Press.

Porter, M. E. (1985). Competitive advantage. New York, NY: Free Press.

Porter, M. E. (1991). Towards a dynamic theory of strategy. Strategic Management Journal, 12(Winter), 95-117.

Prince, J. T., \& Simon, D. H. (2015). Do incumbents improve service quality in response to entry? Evidence from Airlines' on-time performance. Management Science, 61(2), 372-390.

Rivkin, J. (2000). Imitation of complex strategies. Management Science, 46(6), 824-844.

Ross, J., \& Sharapov, D. (2015). When the leader follows: Avoiding dethronement through imitation. Academy of Management Journal, 58(3), 658-679.

Schmalensee, R. (1978). Entry deterrence in the ready-to-eat breakfast cereal industry. Bell Journal of Economics, 9 (2), 305-327.

Seamans, R. C. (2013). Threat of entry, asymmetric information, and pricing. Strategic Management Journal, 34(4), 426-444.

Seamans, R., \& Zhu, F. (2017). Repositioning and cost-cutting: The impact of competition on platform strategies. Strategy Science, 2(2), 83-89.

Simon, D. (2005). Incumbent pricing responses to entry. Strategic Management Journal, 26(13), 1229-1248.

Spence, A. M. (1977). Entry, capacity, investment and oligopolistic pricing. The Bell Journal of Economics, 8(2), 534-544.

Stackelberg, H. F. V. (1934). Market structure and equilibrium, Springer Science \& Business Media (Translated version 2010).

The Economist. (2012, 21 January). Aircraft leasing: Buy or rent?

Transportation Research Board National Research Council. (1999). Entry and competition in the US airline industry: Issues and opportunitiesSpecial Report No. 255). Washington, DC: The National Academies Press.

Williams, J. W. (2013). Capacity investments, exclusionary behavior, and welfare: A dynamic model of competition in the airline industry (Working paper). Retrieved from https://ssrn.com/abstract=1375450, SSRN.

Windle, R., \& Dresner, M. (1999). Competitive responses to low cost carrier entry. Transportation Research Part E: Logistics and Transportation Review, 35(1), 59-75.

\section{SUPPORTING INFORMATION}

Additional supporting information may be found online in the Supporting Information section at the end of this article.

How to cite this article: Ethiraj S, Zhou YM. Fight or flight? Market positions, submarket interdependencies, and strategic responses to entry threats. Strat Mgmt J. 2019;40:1545-1569. https://doi.org/10.1002/smj.3044 